tropics. For this case, the 'optimum' $T_{\mathrm{b}}$ for water economy is about $32.5^{\circ} \mathrm{C}$, but the lowest corresponding rate of evaporation is several times the minimum possible. Clearly, excessive insulation in the tropics can adversely affect water economy.

We conclude that the observed values of the body temperatures for most homoiotherms, between about $35^{\circ} \mathrm{C}$ and $43{ }^{\circ} \mathrm{C}$, are consistent with determination by the requirements of the heat balance. In particular, this range of body temperatures is predicted by considering the need to minimize both energy expenditure in the cold and water loss in warm conditions. High insulation is obviously necessary for homoiothermy in the cold, but a reasonable amount of insulation is also required if body temperature is to be kept constant in a warm environment.

Poorly insulated homoiotherms can be regarded as a different class. In a warm environment, they can minimize both water loss and metabolic rate, but only by permitting a thermolabile body temperature. Therefore, if the dinosaurs had thermoregulated like monotremes they would have been more at risk from sudden climatic changes than relatively well insulated animals, but more favoured in a period of stable climate.

Lastly, in what conditions could homoiotherms evolve on other planets? For an aqueous biota obtaining its energy from the oxidation of carbon compounds and its oxygen from a gaseous atmosphere, similar mechanisms of heat dissipation will occur. The latent heat of vaporization of water changes only slowly over the temperature range of interest, from $2,500 \mathrm{~J} \mathrm{~g}^{-1}$ at $0^{\circ} \mathrm{C}$ to $2,400 \mathrm{~J} \mathrm{~g}^{-1}$ at $40^{\circ} \mathrm{C}$, so that the potential for evaporative cooling will be similar for all such life forms. Theoretically, the potential for sensible heat loss will depend on atmospheric composition and pressure, but in practice the insulation of fibrous coats is likely to differ little from that of terrestrial animals, because the thermal conductivity of gases changes little with realistic ranges of pressure and atmospheric composition. We conclude that biota employing biochemistry and media similar to those on Earth can only evolve true homoiotherms with a similar range of body temperatures, between about $35^{\circ} \mathrm{C}$ and $43^{\circ} \mathrm{C}$. If intelligent life requires a high metabolic rate and homoiothermy, it may therefore be able to evolve only on planets with a relatively narrow range of climates.

Alastair J. McArthur

\section{Department of Physiology} Jeremy A. Clark

and Environmental Science,

University of Nottingham,

Sutton Bonington,

Loughborough LE12 SRD, UK

1. Paul, J. Nature 323, 3(K) (1986)

2. Dunitz, J.D. \& Benner, S.A. Nature 324, 418 (1986)

3. Calder, W.A. Nature 324, 418 (1986).

\section{A cautionary view of antifertility vaccines}

SIR-K.J. Jayaraman's news report ${ }^{1}$ of trials of antifertility vaccines comprising gonadotropin hormone subunits and their derivatives calls for some comment. First, it is not quite correct to state that one 'cocktail' of antigens and carriers used by G.P. Talwar for vaccination consists of oLH-hCG-TT (ovine luteinizing hormone-human chorionic gonadotropintetanus toxoid) and oLH-hCG coupled to cholera toxoid chain B (CHB), and a second mixture of oLH-TT-CHB and hCG-TT-CHB. In fact, the vaccines either contain the $\alpha$-subunit of oLH $(\alpha$ oLH) combined with the $\beta$-subunit of hCG $(\beta-h C G)$ coupled to the two carriers, or $\beta$-oLH-TT-CHB and $\beta$ hCG-TT-CHB. A third vaccine, which was not mentioned, employs $\beta$-hCG - TT alone (for review see ref. 2 ).

More importantly, doubts arise concerning the hormone specificity, and therefore the safety, of the antifertility vaccines which either already are in phase I clinical trials or are planned to be by the Population Council and the Indian Institute of Immunology. Both groups claim that their carrier-coupled antigens are safe on the basis that $\alpha$-oLH, $\beta$-hCG, $\beta$ oLH and $\alpha$-oLH/ $\beta-h C G$ are either species-specific (because $\alpha$-oLH and the $\alpha$-chain of human glycoprotein hormones are considered immunologically distinct) or, if antibodies against $\mathrm{hLH}$ are elicited (because of similarities between $\beta$-hLH and $\beta$-hCG) they would cause no side effects. The first assumption is based on a concept of Vaitukaitis ${ }^{3}$ which no longer holds true; only three monoclonal antibody-defined human $\alpha$-chain epitopes support the assumption ${ }^{4}$, whereas three other epitopes - one of which is only expressed by the non-assembled chain are not only shared by all $\alpha$-subunits of human glycoprotein hormones but are also present on $\alpha$-oLH.

Concerning the immunological specificity of $\beta$-oLH and $\beta$-hCG chains compared with $\beta$-hLH, the situation is even worse. As Jayaraman states, there are numerous reports of immunological crossreactivities (for example ref. 3). Monoclonal antibody based analyses reveal at least three epitopes shared between the two human $\beta$-chains ${ }^{4,5}$, two of which are also common to oLH. Moreover, monoclonal antibodies against all these shared epitopes are able to inhibit the receptor binding ability of hCG as well as hLH. Additional side effects on the target cell from $\beta$-oLH $/ \beta$-hCG vaccination might also be caused by antibodies which still have access to the receptor-bound hormone.

One possible way of circumventing the problem of shared epitopes would be to use for vaccination the hCG-specific carboxy-terminal peptide as done by V.C. Stevens and applied in the WHO supervised Australian trial ${ }^{2.7}$. If this turns out to be of poor antigenicity, as suggested by Talwar, it would be necessary to investigate further the truly hCG-specific epitopes $^{4}$ and try to isolate them or to construct appropriate mimotopes ${ }^{5}$. All other nonspecific vaccines have to be regarded with scepticism until their safety is clearly proven bearing in mind that they will eventually be applied to millions of people.

\section{Institute for General and Experimental} Pathology,

University of Innsbruck Medical School, Fritz-Pregl-Strasse 3,

A-6020 Innsbruck, Austria

1. Jayaraman, K. Nature 323, 661 (1986).

2. Stevens, V.C. Immun. Today 7. 369-374 (1986).

3. Vaitukaitis. J.L. in Structure and Function of the Gonadotropins (ed. McKerns, K.W.) 339-360 (Plenum. New York. 1978).

4. Schwarz, S.. Berger. P. \& Wick. G. Endocrinology 118 $189-197$ (1986)

5ofler, R. Berger. P. \& Wick. G. Am. J. reprod. Immunol. 2. $212-216(1982)$.

6. Geysen, H.M., Barteling. S.J.\& Meloen. R.H. Proc, natn. Acad. Sci. U.S.A. 82.178-182(1985)

Ada. G.L.. Basten. A. \& Jones. W. R. Nature 317, 288-289 (1985).

\section{Quantitative receptor autoradiography}

SIR-Any article which preaches caution in the quantification of autoradiographs is to be welcomed. But if advice is being offered, surely it is important that it should be based on the best information available. We would therefore like to draw attention to some inaccuracies and misleading generalizations that appear in the article by M.D. Hall, A.P. Davenport and C.R. Clark (Nature 324, 493; 1986).

First, the radionuclide ${ }^{125}$ I does not emit $\beta$-particles, which by definition are electrons of nuclear origin, but mainly Auger electrons. Contrary to the statement of the authors, most of these ( 96 per cent) are less energetic than most of the $\beta$ particles of tritium ( 28 per cent at $2.0 \mathrm{keV}$ and 68 per cent at $0.8 \mathrm{keV})$. It must therefore be assumed that the majority of the higher-energy emissions which sensitize emulsions are X-ray or gamma photons.

Also, in spite of the statement in the article to the contrary, ${ }^{125} \mathrm{I}$-polymer based standards are now commercially available from Amersham International.

The authors further assert that ". . . the anatomical resolution could be greatly enhanced if the crystal diameter of the emulsion used to make the films was reduced significantly ...". This is grossly misleading. It was shown many years ago by Dr Salpeter and co-workers at Cornell University that even at the electron microscopic level of autoradiography, reducing the halide crystal diameter in the emulsion by a factor of three gives an improvement in resolution (a reduction of 